\title{
Definição do perfil de competências em saúde coletiva a partir da experiência de cirurgiões-dentistas atuantes no serviço público
}

\author{
Definition of abilities profile in public health \\ based on the experience of dentists of public service
}

Iris do Céu Clara Costa ${ }^{1}$

Maria NeileTorres de Araújo ${ }^{2}$

${ }^{1}$ Departamento de Odontologia, Centro de Ciências da Saúde, UniversidadeFederal do Rio Grande do Norte. Av. Salgado Filho 1.787, Lagoa N ova. $59056-000 \mathrm{~N}$ atal RN iris_odontoufrn@yahoo.com.br ${ }^{2}$ Céntro de Ciências da Saúde, UniversidadeFederal do Ceará.
Abstract A curriculum by skills should prepare thestudent for a critical and reflectiveknow-how, so that he can feel as an active part of his social context, mobilizing resources to solve problems that appear in the professional exercise. It was investigated the difficulties faced by dentists from the public service of Rio Grande do N orte State about the public health in order to establish a profile of skills for the new vocational curriculum. Data were collected through a questionnaire with a test of free association of words and an interview analyzed by EVOC 2000 and Thematic Content Analysis. The main difficulties found were: working in teams, lack of commitment of managers with the continuity of the health actions, unprepared professionals to face the collective problems, and the precariousness of work. Considering the profile of the health professional suggested by the new curriculum guidelines, the results signal for a need for changes in the curriculum, to graduate professionals compatible with the requirements of the actual labour market, which includes knowledge, know-how and knowbe, with a critic view. Thus, as soon as the courses of Dentistry adhere the changes in education, more likely the new graduated will be able from the view of competencies and skills to deal with possible difficulties.

Key words Competency-based education, Skills, Curricular guidelines
Resumo 0 currículo por competências deverá preparar o aluno para um saber-fazer crítico, reflexivo, ser parte ativa do contexto social, mobilizar recursos, que resolvam problemas surgidos no exercício profissional. Investigou-se, entre cirurgiões-dentistas do serviço público do Rio Grande do $N$ orte, dificuldades em saúde coletiva, para estabelecer um perfil de competências no novo currículo. Coletaram-seos dados pelo teste deassociação livre de palavras e entrevista, analisados pelo EVOC 2000 eanálise de conteúdo. As dificuldades dos entrevistados foram trabalhar em equipe, falta de compromisso dos gestores com a continuidade das ações, despreparo profissional para enfrentar problemas coletivos, além da precarização do trabalho. Considerando o perfil profissional sugerido pelas novas diretrizes curriculares, os resultados sinalizam para mudanças no currículo, fundamentadas nas diretrizes, formando profissionais compatíveis com as exigências do mercado de trabaIho, incluindo as competências saber, saber-fazer, saber-ser, com visão questionadora da própria prática. Quanto mais rápido os cursos de odontologia aderirem asmudanças, mais provavelmenteos profissionais formados a partir delas estarão capacitados do ponto de vista de competências e habilidades para lidar com dificuldades surgidas. Pal avras-chave Educação baseada em competências, Habilidades, Diretrizes curriculares 


\section{Introdução}

No sistema educacional vigente, atribui-se às universidades a tarefa de aprovar, ministrar e reconhecer habilitações. Entretanto, os profissionais são formados para atuar na saúde, sem que exista um diagnóstico concreto com relação as necessidades do setor, o que gera um descompasso entre a formação do aluno e a necessidade dos serviços, transferindo ao setor saúde a responsabilidade de favorecer as condições de capacitações as mais diversas no próprio serviço, para complementar as lacunas da formação acadêmica dos profissionais.

No sentido de construir uma estratégia eficaz para o bom funcionamento dos serviços, é preciso gerar um processo educacional que articule formação profissional com as demandas e necessidades da sociedade, o que poderá possibilitar ao indivíduo o exercício eficiente do seu trabalho, aliado à participação consciente e crítica na esfera social, bem como na sua autorrealização. Isso poderá se tornar possível quando houver uma política pedagógica capaz de repensar a pratica educativa de cunho tecnicista e acrítica representada pela atuação profissional na sua realidade histórica e romper com a dicotomia entre pensar efazer, entre geral e específico, entre habilidades teóricas e práticas ${ }^{1}$.

Para alguns autores ${ }^{2-4}$, essas reflexões não devem se contentar apenas com o processo de aprendizagem no espaço econtexto, mas devem ter como horizonte uma sociedade transformada, isto é, comprometida com um projeto social que tem 0 homem como prioridade essencial e centro dessas preocupações. Como desafio da formação profissional em saúde, as instituições deverão pensar nessa formação voltada para a humanização do homem, a partir da integração de conhecimentos gerais e específicos, habilidades teóricas e práticas, hábitos, atitudes e valores éticos. Isso implica repensar a inserção desse profissional na sociedadee construir sua participação partindo da reflexão, questionamentos e formulação de propostas, fundamentadas na sua realidade vivencial, visando à transformação dessa realidade.

Nessa nova dinâmica do mercado, o profissional deverá diagnosticar, solucionar problemas, ser capaz de tomar decisões, de intervir no processo de trabalho, de trabalhar em equipe. Os pontos dessa dinâmica coincidem com as competências ehabilidades que o profissional de saúde deverá ter segundo as diretrizes curriculares dos cursos da área da saúde, aprovadas pela Sesu/ MEC em $2002^{5}$.
Levando-seem conta as transformações ocorridas no mundo do trabalho, as diretrizes curriculares definem al gumas competências gerais na formação do profissional de saúde. No campo da tomada de decisões, este profissional deverá desenvolver habilidade para avaliar, sistematizar e escolher a conduta mais apropriada. $\mathrm{Na}$ comunicação, deverá ser capaz de interagir com os pacientes/comunidades, além de ter habilidades para comunicação verbal, não verbal, escrita e meios eletrônicos. No que se refere à liderança, são consideradas competências indispensáveis o trabalho em equipe multiprofissional, responsabilidade, empatia, gerenciamento e administração de recursos humanos, físicos e materiais. Quanto à atenção à saúde, o profissional deverá estar apto dentro de um trabalho em equipe a desenvolver ações de promoção, prevenção, proteção er reabilitação no nível individual ecoletivo, contempladas no sistema de saúde vigente e no nível deatenção à saúde egestão queo município se enquadra $a^{4,5}$.

Portanto, considerando que a formação acadêmica deveria preparar o aluno para a realidade do dia a dia profissional, fazendo-o desenvolver habilidades para superar as adversidades e obstáculos, este trabalho surgiu da necessidade de identificar as principais dificuldades vivenciadas na área da saúde coletiva, por cirurgiões-dentistas generalistas atuantes no serviço público, cujos resultados poderão nortear a composição dos conteúdos das disciplinas referentes a essa área temática, na reestruturação do novo currículo, bem como traçar critérios que deverão compor o perfil do novo profissional da odontologia.

\section{Fundamentação teórica}

Alguns trabal hos na área do ensino $0^{1,6-8}$ declaram que as profissões de saúde devem ser medidas pelo nível de saúde da população que utiliza seus serviços enão pela qualificação científica etecnológica dos seus profissionais. A pesar desse pressuposto, o que tem se observado no ensino superior das profissões de saúde é uma enorme divergência entreo queéensinado eo que defato a população precisa.

$\mathrm{Na}$ tentativa de tentar aproximar estes dois contextos (universidade e serviços) fora de sintonia e al gumas vezes divergentes, al guns movimentos sociais ligados à universidade despontaram ao longo do tempo na tentativa de vencer essas diferenças. $\mathrm{N}$ a década de cinquenta, os $\mathrm{De}$ partamentos de M edicina Preventiva surgiram 
na perspectiva de aliar saúde pública com medicina liberal. Outros movimentos como a medicina comunitária e a integração docente-assistencial (IDA) foram importantes como primeiras experiências aliadas à participação comunitáriae voluntariada na prestação de serviços, além de, no caso da IDA, tentar quebrar a resistência dos estudantes quanto à abordagem social e epidemiológica das doenças $\mathrm{s}^{6,7}$.

O próprio Sistema Ú nico de Saúde (SUS) no Brasil acumulou política etecnicamenteboa partedas experiências demedicina comunitária eIDA no esboço da sua construção, por que absorveu ou foi construído fundamentado nos princípios da Reforma Sanitária e de todas as experiências de saúde coletiva anteriores a ela ${ }^{4,5}$. No Brasil, em função das novas exigências do mercado de trabalho, com novos cenários de prática, se trabalha a interdisciplinaridade, se realizam ações educativas que estimulam a integração ensinopesquisa-serviço, se exige um compromisso ético, humanístico e social com o trabalho multiprofissional, os quais solicitam um profissional mais generalista e de formação mais ampla. A partir dessa exigência, surgeuma profunda preocupação: a de repensar a formação dos novos profissionais, ainda preparados numa abordagem individual e curativa, incapazes de extrapolar o espaço da clínica e propor um diagnóstico sobre o coletivo e suas interven çõe ${ }^{4,5}$.

A diversidade dos cenários de prática é um ponto importante na construção desse processo, pois é fundamental que os profissionais, enquanto alunos, conheçam os vários espaços de prestação de serviços. Por outro lado, as mudanças almejadas na formação do profissional têm que ser construídas a partir da reflexão crítica de todos os segmentos participantes da atenção, como universidade (professores, alunos e dirigentes), serviços de saúde (gestores e profissionais) e população (usuários, conselhos municipais de saúde). As mudanças são complexas e, para concretizá-las, as universidades precisam de apoio técnico e político, o qual deverá ser traduzido por um trabalho articulado entre os $\mathrm{Mi}$ nistérios da Educação eda Saúde, proporcionando a formação dos formadores, atividades de capacitação e debates entre os segmentos interessados (docentes, discentes, serviços e usuári0s) 7,8 .

Embora se destaque a importância da diversidade dos cenários, a formação por competências é hoje o foco principal na elaboração dos projetos político-pedagógicos, tanto para a educação básica como para a educação superior. N esse sen- tido, a atual Lei deD iretrizes e Bases da Educação Nacional (LDB) define competências como a "capacidade de mobilizar, articular, colocar em ação valores, habilidades e conhecimentos necessários para o desempenho eficientee eficaz deatividades requeridas pela natureza do trabalho" ${ }^{\prime \prime}$.

Quanto à estruturação de um currículo por competências, significa preparar os alunos para um saber-fazer reflexivo, crítico, o suficientepara que $o$ aluno sinta-se participante do seu contexto social, o que Ihe permitirá decidir, utilizar, modificar e mobilizar recursos disponíveis para resolver com sucesso, problemas surgidos na prática profissional. Um currículo por competências é fundamentado na análise de situações: como uma via de mão dupla, parteda teoria para a prática, do concreto para 0 abstrato, do real para o conceitual e vice-versa em todas as situações. Assim, uma reformulação curricular por competências implica ter uma estrutura curricular que ultrapasse de fato programas tradicionais na sua práxis e não se limitar somente à utilização de um verbo de ação que inicia a descrição dos conteúdos disciplinares. Em outras palavras, é colocar a educação a serviço das necessidades concretas do aluno, no que se refere ao seu preparo para o início do exercício profissional 10,11. O Quadro 1 propõe uma organização curricular por competências, que deverá englobar novas estratégias e metodologias de ensino, a avaliação por competências e a adoção de um contexto interdisciplinar do ensino.

Para compreender-se o sentido de competências, é interessante destacar al guns conceitos encontrados na literatura. Competências fazem

Quadro 1. Formação por competências.

\begin{tabular}{|l|l|}
\hline \multicolumn{1}{|c|}{ Paradigma em superação } & Paradigma em implantação \\
\hline Aula expositiva & Problematização \\
\hline Professor especialista & Professor facilitador \\
\hline Disciplina isolada & Interdisciplinaridade \\
\hline Teoria versus prática & Contextualização \\
\hline Sala de aula & Ambiente de formação \\
\hline Conteúdo & Competência \\
\hline A prender & Aprender a aprender \\
\hline Avaliação & Acompanhamento \\
\hline Turmas homogêneas & Turmas heterogêneas \\
\hline Registro de notas & Registro de resultados \\
\hline
\end{tabular}

Fonte: Souza ${ }^{11}$. 
parte dos esquemas mentais, isto é, as ações e operações mentais de origem cognitiva, socioafetiva ou psicomotora, que estimuladas eassociadas simultaneamente a saberes teóricos ou experimentais, geram habilidades relativas ao saber-fazer ${ }^{12}$.

Pode-seainda descrever competência como a atitude para desenvolver as atividades profissionais, tendo como principais componentes a organização e planejamento do trabalho, a inovação e capacidade para resolver atividades não rotineiras, incluindo a capacidadenecessária para relacionar-se com pessoas as mais diversas ${ }^{10,13}$.

O utro conceito sobre competência compreende-a como sendo a capacidade de agir com saber e com consciência sobre as consequências desse agir ${ }^{14}$. Finalmente, pode-se falar de competência como a capacidade de atuar de forma eficaz, fundamentada em saberes e conhecimentos, mas sem limitar-se a eles. Assim, pode-se dizer que um sujeito competente é o que julga, avalia, pondera, encontra solução e decide adequadamente qualquer situação, após examinála e discuti-la da maneira mais conveniente ${ }^{15,16}$.

Dos conceitos expressos, apreendemos que competência é um processo e não um produto, ou seja, não existe um sujeito completamente competente ou plenamente competente. Tanto as competências quanto 0 indivíduo competente não são algo prontos, mas são construídos no dia a dia, no decorrer do desenvolvimento profissional, tendo como ponto de partida a formação inicial. Portanto, o competente não éum ser superior, mas é aquele que, diante de problemas difíceis, ajuda a encontrar caminhos e soluções sensíveis ecriativas que uma pessoa mediana não encontraria.

\section{Métodos}

Esta pesquisa foi concebida como tarefa final do I Curso de Ativadores de mudanças na formação profissional em saúde, promovido pelo M inistério da Saúde, Escola Nacional de Saúde Pública Sérgio Arouca (ENSP) da Fiocruz e RedeUnida.

A amostragem foi do tipo probabilística por conveniência, baseada no critério da acessibilidade. Assim, considerando as características conveniência e acessibilidade, em vez de ir às unidades de saúde para coletar os dados, optou-se por entrevistar profissionais que estavam cursando a primeira semana de aulas das especializações de Saúde Coletiva e Odontologia do Trabalho no município de $N$ atal (RN), mas que exercem suas atividades no serviço público em diversos municípios do estado. 0 grupo de entrevistados não tinha nenhuma formação na área objeto de estudo, estava apenas no início dos respectivos cursos de especialização, são todosoriundos deuma formação generalista, o que acreditamos não tenha influenciado suas respostas, uma vez que procuraram essas especialidades tanto para, segundo eles, suprirem lacunas deixadas pela graduação, no que se refereà preparação do profissional para o exercício público, quanto por sentirem necessidade de complementar conhecimentos ligados à área. Todos os entrevistados são atuantes na atenção primária do Sistema Único de Saúde (SUS), alguns no Programa Saúde da Família e outros em unidades de saúde tradicionais da rede básica do SUS no Estado do Rio Grande do Norte. Portanto, a amostra foi constituída por 46 cirurgiões-dentistas, 34 do sexo feminino edozedo sexo masculino, com tempo de formado agrupado em quatro intervalos, de um a cinco anos, de seis a dez anos, de onze a quinze anos e com mais de quinze anos de formado.

Quem sabe, noutro momento, essa investigação possa ser complementada, usando-se um grupo amostral também atuante no serviço público, mas sem já estarem cursando especialidades afins com o objeto de estudo dessa investigação, para eventuais comparações e eliminação de possíveis influências nos resultados.

Utilizou-se como instrumento de coleta um formulário contendo dois itens: o teste de associação livre de palavras e uma questão geradora aberta. Sobre o teste de associação livre de palavras, éo mais antigo dostestes projetivos utilizados em psicologia clínica e ajuda a localizar zonas de bloqueamento de um indivíduo, permitindo que apareçam espontaneamente associações relativas à palavra indutora. 0 que caracteriza o formulário é o contato face a face entre pesquisador e entrevistado, além das respostas às perguntas serem preenchidas no momento da entrevista, otimizando a coleta de dados ${ }^{17}$.

Toda a investigação foi realizada dentro dos princípios éticos contidos na Resolução n 196/ 96 do Conselho N acional de Saúde. Antes da coleta, na fase de recrutamento e seleção, foram explicitados aos sujeitos os objetivos da pesquisa para obtenção do termo de consentimento livre e esclarecido (TCLE). A partir dos critérios de inclusão (ter um ano ou mais de atuação no serviço público, ter disponibilidade de tempo para responder ao formulário e querer participar) e da obtenção do TCLE, o formulário foi entregue aos sujeitos selecionados para preenchimento. No 
primeiro item (referente ao teste de associação), pedia-se ao indivíduo que escrevesse no espaço apropriado três palavras que ele lembrava, ao ouvir a expressão indutora "saúde coletiva". Em seguida, eledeveria escolher aquela que, sozinha, fosse suficientemente expressiva para representar, do ponto de vista dos significados, o tema abordado, justificando a sua escolha. É interessante lembrar que, antes de se entregar o formulário para resposta, foram feitos alguns ensaios com outras palavras indutoras, para compreensão adequada da utilização do teste. No segundo item, foi solicitado aos entrevistados que respondessem à questão geradora sobre "quais as dificuldades ou facilidades na área de saúde coletiva que você encontrou durante o seu exercício profissional", no sentido de complementar e aprofundar os significados das evocações obtidas no teste de associação aplicado no item anterior.

Quanto à análise dos dados, aqueles pertinentes ao teste de associação, representados na Quadro 2, foram analisados e comparados entre si a partir de uma análise quantitativa executada pelo software EVOC 2000, tomando-se por base a frequência ( $F$ ) e a ordem média de evocação $(\mathrm{OME})^{19,20}$. Para tal, as palavras foram organizadas através deum processo de classificação, agrupando-se as palavras idênticas ou similares por aproximação dos sentidos semânticos, com a finalidadedeestabelecer as categorias deanálisepara posterior descrição e compreensão das evocações a partir da teoria do núcleo central ${ }^{17}$.

0 Quadro 2 apresenta 0 eixo das abscissas $(x)$ que corresponde aos valores referentes às ordens médias de evocação (OME) e o eixo das ordenadas (y), que corresponde aos valores da frequência. Desse modo, cada evocação corresponde a um ponto no gráfico, que sugere uma correlação positiva entre as variáveis. As evocações que figuram no quadrante superior esquerdo dessa figura são as que mais provavelmente fazem parte do núcleo central. As que estão no quadrante inferior direito pertencem ao sistema periférico, enquanto as demais são consideradas pertencentes ao sistema intermediário. 0 núcleo central determina a natureza dos laços que unem entre si os elementos da representação e é nesse sentido o elemento unificador e estabilizador da mesma. Eleédeterminado, por um lado, pela natureza do objeto representado; por outro lado, pela relação que o sujeito mantém com esse objeto. Em torno do núcleo central, se distribuem os elementos periféricos da representação, queatualizam e contextualizam as determinações normativas do núcleo central. Diferentemente deste, 0 sistema periférico éflexível emais sensível ao contexto imediato, sendo nele, portanto, que devem se concentrar as estratégias que visem interferir no núcleo das representações de um grupo ${ }^{17}$. Por sua vez, as falas obtidas através da pergunta geradora passaram também pelo processo de categorização, cujas categorias foram descritas e interpretadas pela análise de conteúdo temática de Bardin ${ }^{18}$.

A análise de conteúdo é uma maneira de re velar o que há de significante nas comunicações escritas pelos profissionais, no que diz respeito ao objeto de estudo; nesse caso, a saúde coletiva. Assim, esta técnica, enquanto analisa as condições de produção do discurso, efetua inferências sobre as mensagens inventariadas e sistematizadas, articulando o discurso com o contexto de produção. Após a leitura flutuante do material gerado, foram definidas as categorias (facilidades e dificuldades), para posterior descrição, articulação e entendimento das mesmas ${ }^{18}$.

Quadro 2. I dentificação dos possíveis elementos do núcleo central sobre saúde coletiva por dentistas atuantes no serviço público. Natal (RN), 2007.

\begin{tabular}{|ll|ll|}
\hline $\begin{array}{l}\text { OME <2,00 e F }>16 \\
\text { Cidadania (20) }\end{array}$ & $\begin{array}{l}\text { OME }>2,00 \text { e F }>16 \\
\text { Prevenção (25) }\end{array}$ \\
$\begin{array}{l}\text { Educação(16) } \\
\text { Qualidade de vida(19) }\end{array}$ & 1,90 & \\
\hline OME <2,00 e F <16 & 1,62 & OM E > 2,00 e F <16 \\
Planejamento (14) & 1,84 & Compromisso (10) \\
& Parceria (10) & 2,30 \\
& & PSF (13) & 2,60 \\
\hline
\end{tabular}

Fonte: Vergès ${ }^{19}$, Vergès ${ }^{20}$. 


\section{Resultados ediscussão}

A saúde coletiva representa a área do conhecimento que mais apresenta relações de interface com o serviço público de assistência e agrupa saberes os mais diversos. Embora isso seja verdadeiro do ponto de vista teórico, na prática, os profissionais da área da saúde e, dentre estes, os da odontologia, sentem grande dificuldade de atuação, por terem recebido, na maioria das vezes, uma formação acadêmica voltada para a clínica privada, que privilegia as técnicas e está voltada quase que exclusivamente para o nível individual de atuação. A pesar dessas dificuldades, os profissionais entrevistados entenderam a saúde coletiva como uma área plural e atraente, cujos significados estão mostrados no Quadro 3.

0 Q uadro 3 representa 0 agrupamento das palavras evocadas no teste de associação livre na sequência ordenada de aparecimento. A palavra "prevenção" foi a que teve maior frequência (25), embora não tenha sido a mais evocada na primeira colocação, seguida de "cidadania" (20), "qualidade devida" (19) e"educação" (16). A partir desse agrupamento e após a análise do EVOC 200019,20, encontramos o núcleo central da saúde coletiva, presente no ideário das pessoas entrevistadas, associado ao exercício da cidadania, educação equalidade de vida, queancoradosna prevenção, representam os fundamentos da saúde coletiva.

As palavras evocadas pelos entrevistados (Quadro 2) para representar a saúde coletiva foram repletas de significados e resumem qualidades que fazem parte do saber, saber-fazer e saber- ser, em cuja essência estão fundamentadas as novas competências curriculares na área da saúde.

Embora as palavras humanização e interdisciplinaridade tenham apresentado as menores frequências de evocação, é mister destacar a importância de terem sido lembradas, haja vista estarem contempladas no contexto de algumas das novas competências gerais na formação dos profissionais da saúde, como atenção à saúde e intersetorialidade, respectivamente.

Conforme mostra a Figura 1 e baseados na teoria do núcleo central ${ }^{17}$, as três palavras que aparecem no quadrante superior direito (cidadania, educação e qualidade de vida) são os prováveisnúcleos centrais das representações sobresaúde coletiva, seguidas de compromisso, parceria e PSF como sistema periférico, além de prevenção e planejamento como elementos intermediários.

Considerando quecompetenteéaqueleindivíduo quetem a capacidade deagir com consciência ecriatividade, mesmo diantedeproblemas difíceis, - Quadro 4 resume as dificuldades e facilidades que os profissionais tiveram no exercício da odontologia no serviço público e ilustra situações que foram enquadradas nessas categorias, as quais, trabalhadas dentro dos conteúdos curriculares do organismo formador, poderão ajudar o aluno desde cedo a buscar soluções e aprender a encontrar caminhos, estimulando o pensamento crítico, re flexivo e norteando sua formação.

Como pode se ver no Quadro 4, no que se refere à categoria "facilidades encontradas", os entrevistados apontam o serviço público como sendo um "campo de trabalho atraente", na medida em que Ihes proporciona uma diversidade

Quadro 3. Resultado do teste de associação livre de palavras, a partir da expressão "saúde coletiva" como estímulo indutor. Natal (RN), 2007.

\begin{tabular}{|l|c|c|c|c|c|}
\hline \multicolumn{1}{|c|}{ Palavras } & 1a Evoc. & 2a Evoc. & 3a Evoc. & F & OM E \\
\hline Cidadania & 4 & 6 & 10 & 20 & 1,90 \\
\hline Compromisso & 2 & 4 & 4 & 10 & 2,30 \\
\hline Educação & 8 & 3 & 5 & 16 & 1,62 \\
\hline Humanização & 2 & 2 & 0 & 04 & 2,50 \\
\hline Interdisciplinaridade & 3 & 1 & 3 & 07 & 2,00 \\
\hline Parceria & 5 & 3 & 2 & 10 & 2,60 \\
\hline Planejamento & 3 & 3 & 8 & 14 & 1,93 \\
\hline Prevenção & 6 & 9 & 10 & 25 & 2,20 \\
\hline PSF & 4 & 5 & 4 & 13 & 2,00 \\
\hline Qualidade de vida & 6 & 7 & 6 & 19 & 1,84 \\
\hline
\end{tabular}

F=Frequência; OM E = Ordem média de evocação. 
Quadro 4. Facilidades e/ou dificuldades na área de saúde coletiva, encontradas pelos entrevistados no exercício profissional no serviço público. Natal (RN), 2007.

\begin{tabular}{|c|c|c|}
\hline Categorias & Subcategorias & Frequência \\
\hline \multirow[t]{7}{*}{ Facilidades } & A poio para educação continuada & 3 \\
\hline & Atender um grande número de pessoas & 6 \\
\hline & Campo de trabalho atraente & 5 \\
\hline & Flexibilidade de horários & 2 \\
\hline & Receptividade dos profissionais para as mudanças & 4 \\
\hline & Receptividade dos usuários & 12 \\
\hline & Simplicidade das técnicas & 6 \\
\hline \multirow{11}{*}{ Dificuldades } & Acesso deficiente ao SUS gerando alta demanda & 7 \\
\hline & Baixa resolutividade do SUS & 2 \\
\hline & Despreparo/desinteresse dos profissionais & 18 \\
\hline & Estrutura física deficiente & 12 \\
\hline & Falta de compromisso dos gestores & 21 \\
\hline & Falta humanização e visão preventiva nos profissionais & 12 \\
\hline & Falta de material educativo & 8 \\
\hline & Falta de planejamento e continuidade das ações & 9 \\
\hline & Precarização do trabalho & 3 \\
\hline & Trabalhar em equipe & 8 \\
\hline & Valorização do tratamento curativo pelos usuários e gestores & 17 \\
\hline
\end{tabular}

Fonte: Bardin ${ }^{18}$.

de situações, com as quais se aprende na prática, especial mente a agilidade de raciocínio, de autonomia ede execu ção, visto que "atende um grande número de pessoas", com "simplicidade nas técnicas" enum "horário mais flexível". Além disso, o serviço público oferece "apoio para educação continuada", tanto oferecida pelo próprio serviço, quanto pelo profissional, quando possibilita queele busque seus espaços de crescimento pessoal, o que de certa forma acaba gerando "re ceptividade pelos profissionais para mudanças". Por fim, uma das facilidades apontadas com maior frequência foi a "receptividade dos usuários", o que denota um clima de trabalho favorável, na medida em que a população valoriza o que recebe. Isso mostra a importância de ainda na graduação 0 aluno participar de atividades extramuros, cujas situações encontradas estimulem o potencial criador e desde cedo o coloque diante defatos que exijam o desenvolvimento de competências e habilidades para resolvêlos.

Quanto à categoria "dificuldades encontradas", segundo interpretação ancorada em $\operatorname{Bardin}^{18}$, a "falta de compromisso dos gestores" ( $F=21$ ) foi a mais citada, seguida pelo "despreparo/desinteresse dos profissionais" ( $F=18$ ) em lidar com situa- ções adversas relacionadas à complexidade e burocracia do serviço público. Outro ponto importante com frequência 17 foi a "valorização do tratamento curativo pel os usuários e gestores", mostrando a necessidade de sensibilizá-los para compreender a importância da educação como o grande agente de transformação social e da prevenção como 0 instrumento que deve ser trabalhado paralelamente ao tratamento curativo, de modo a reduzir as demandas futuras e os custos das atividades desenvolvidas. Interessante ressaltar que a "falta dehumanização evisão preventiva dos profissionais" citada em duas evocações vem reiterar o item colocado anteriormente, sinalizando a necessidade de adequação dos temas trabalhados nos conteúdos da graduação.

Sobrea valorização do tratamento curativo e a falta de humanização e visão preventiva dos profissionais, Ceccim ${ }^{3}$ comenta que só haverá mudanças no perfil epidemiológico dos diversos agravos à saúde quando os saberes formais estiverem implicados com movimentos de autoanálise e autogestão das atividades coletivas, uma vez que os atores (profissionais e usuários) dos serviços é que devem ser os protagonistas das mudanças que a realidade exige. 
O utras dificuldades foram citadas no decorrer do processo de categorização, tais como "estrutura física deficiente" ( $F=12$ ), "falta de planejamento e continuidade das ações" ( $F=9)$, que originam provavelmente problemas de "acesso deficiente ao SUS", gerando consequentemente uma demanda reprimida, mostrando uma "baixa resolutividade", além da "falta de material educativo", que corrobora a valorização do tratamento curativo já colocado anteriormente.

A respeito de alguns dos pontos descritos, Feuerwerker ${ }^{7}$, Amoretti ${ }^{6}$, Galassi et al. ${ }^{8} \mathrm{e}$ Garbin et al. ${ }^{1}$ afirmam que as profissões de saúde devem ser avaliadas não pela complexidade da capacidade científica e tecnológica dos seus profissionais, mas pelos padrões de saúde da população que depende dos seus serviços, o que mostra uma estreita relação com a falta de planejamento e continuidade das ações, com a falta de material educativo e com o fato dos profissionais não saberem trabalhar em equipe, o que poderá gerar uma descontinuidade de ações e de conhecimento.

Finalmente, a dificuldade de "trabalhar em equipe" apareceu de forma interessante, considerando-se especialmente que essa modalidade laboral vem cada vez mais se consolidando a partir da estratégia de saúde da família, para a qual os nossos alunos deverão estar preparados, visto que o serviço público é o maior empregador, ainda que a "precarização do trabalho", citada como mais uma das dificuldades encontradas, possa ser discutida paralelamente em fóruns específicos e oportunos.

\section{Consideraçõesfinais}

Os resultados mostraram que os profissionais anal isados apresentaram algumas dificuldades no seu exercício profissional no setor público, especialmente e de forma mais expressiva ligadas à gestão e planejamento, como falta de compromisso dos gestores, especialmente em dar continuidade as ações de saúde, o seu próprio desinteresse e/ou despreparo em lidar com a burocracia presente nos serviços e com situações adversas relativas aos mesmos, atividades descoordenadas e sem continuidade, executadas de forma aleatória, o trabalho em equipe, dentre outras. Percebeu-seque o nível de dificuldades encontrado independeu do tempo de formado e a variável sexo também não interferiu na forma de lidar com e superar essas dificuldades.

0 que é comum a todos, independente do cruzamento de qual quer variável, équeo excesso de tecnologias que surge a todo o momento na odontologia se contrapõe ao acesso precário do usuário aos serviços de saúde, aliado ao despreparo do profissional no enfrentamento dos problemas de gestão, recursos, alta demanda, baixa tecnologia, tão comuns no serviço público.

Sabe-se que a mudança na formação énecessária mas também, por si só, não é tudo. Ela deverá ser incorporada como política e se instalar nas várias dimensões do ensino, dos serviços, no entendimento dos gestores sobre a instituição pública, na forma de ensinar dos docentes, no interesse dos alunos em aprender. Enfim, todos os segmentos envolvidos deverão discutir coisas comuns, pois para que as reformas curriculares aconteçam, é preciso existir um elemento de identidade, um mesmo foco que una as pessoas. Uma das questões fundamentais a considerar é como educar os educadores, tutores e preceptores, para que isso se reverta às necessidades e demandas sociais da área da saúde. Outro ponto importanteécapacitar os gestores para um entendimento amplo do setor público, cujos interesses devem estar voltados para o usuário.

Assim, como traços do perfil profissional da área da saúde, incluindo o da odontologia, que o mercado de trabalho hoje exige podemos citar: desenvolver uma visão crítica ereflexiva sobresua profissão e suas práticas; se apropriar de saberes das ciências humanas e sociais capazes de favore cer essa criticidadee reflexividade; manter erenovar permanentemente os saberestécnicos, somando a eles outros conhecimentos como a epidemiologia, técnicas de abordagens de grupos, práticas interdisciplinares emultiprofissionais; ampliar os domínios da saúde coletiva, gestão de saúde e planejamento segundo as diretrizes do SUS; incorporar conhecimentos de educação e promoção de saúde, de técnicas pedagógicas, de modo que a atenção à saúde seja favorecida.

Finalmente, a partir das propostas de mudança na formação profissional em saúde, orientadas pelas novas diretrizes curriculares, espera-se formar profissionais críticos, aptos a de senvolver ações de promoção, prevenção, proteção e reabilitação da saúde, capazes de trabalhar em equipe e de levar em conta a realidade epidemiológica e social para, embasados nesses princípios, prestar uma atenção à saúde mais humana e de qualidade. Portanto, quanto mais cedo os cursos de odontologia aderirem às novas diretrizes na formação acadêmica, mais provavelmente os profissionais formados a partir de las estarão capacitados do ponto de vista de competências e habilidades para lidar com dificuldades surgidas e assim contribuir para um Sistema ú nico de Saúde pleno e resolutivo. 


\section{Colaboradores}

ICC Costa concebeu, delineou, realizou a pesquisa e redigiu o artigo; M NT Araújo analisou a metodologia e auxiliou a redação final.

\section{Referências}

1. Garbin CAS, Saliba NA, M oimaz SAS, Santos KT. O papel das Universidades na formação de profissionais na área de saúde. Rev da ABENO 2006; 6(1):610.

2. Amâncio Filho A. Dilemas e desafios da formação profissional em saúde. Interface (Botucatu) 2004; 8(15):375-380.

3. Ceccim RB. Educação permanente em saúde: desafio ambicioso e necessário. Interface (Botucatu) 2004; 9(16):161-177.

4. Costa ICC. Os sete saberes necessários à educação do futuro e o planejamento das ações de saúde: algumas reflexões e confluências. Rev da ABENO 2007; 7(2):122-129.

5. Brasil. M inistério da Educação. Diretrizes Curriculares Nacionais dos Cursos de Graduação em Farmácia e Odontologia. Brasília: Conselho Nacional de Educação; 2002.

6. Amoretti R. A educação médica diante das necessidades sociais em saúde. Rev Bras Educ M éd. 2005; 29(2):136-146.

7. Feuerwerker LCM . Educação dos profissionais de Saúde hoje: problemas, desafios, perspectivas e as propostas do Ministério da Saúde. Rev da ABENO 2003; 3(1):24-27.

8. Galassi MAS, Barbin EL, Spanó JCE, M elo JAJ, Tortamano N, Carvalho ACP. Atividades extramuros como estratégia viável no processo ensinoaprendizagem. Rev da ABEN 0 2006; 6(1):66-69.

9. Universidade Federal do Rio Grande do Norte. Lei de Diretrizes e Bases da educação nacional - LDB Estatuto e Regimento geral da UFRN / M inistério da Educação e do Desporto. Natal: EDUFRN; 1998.

10. Nunez IB, Ramalho BL. Competência como fio condutor na formação profissional: 0 desafio possível. In: Oliveira VQSF, organizador. 0 sentido das competências no projeto político-pedagógico. $\mathrm{N}$ atal: EDUFRN; 2002. p. 33-50.

11. Souza ZR. Pressupostos para formação por competências. In: Oliveira VQSF, organizador. 0 sentido das competências no projeto político-pedagógico. Natal: EDUFRN; 2002. p. 51-58.
12. Berger LR. Currículo por competências. [site da Internet] [acessado 2006 jun 02]. Disponível em: http://www.mec.gov.br

13. Lima VV. Competência: distintas abordagens e implicações na formação de profissionais de saúde. Interface (Botucatu) 2005; 9(17):161-167.

14. Bar G. Perfil y competências del docente en el contexto institucional educativo. In: I Seminário Taller sobre perfil del docente y estratégias del formación; 1999; Lima.

15. Nunez IB, Ramalho BL. Competência: uma reflexão sobre o seu sentido. In: Oliveira VQSF, organizador. 0 sentido das competências no projeto políticopedagógico. Natal: EDUFRN; 2002. p. 11-32.

16. Perrenoud P. Construir as competências desde a escola. Porto Alegre: Artmed; 1999.

17. Abric JC. A abordagem estrutural das representações sociais. In: Moreira ASP, Oliveira DC, organizadores. Estudos interdisciplinares de representação social. Goiânia: AB; 1998. p.27-38.

18. Bardin L. Análise de conteúdo. Lisboa: Edições 70; 1995.

19. Vergès $P$. Ensemble de programmes permettant I'analyse des evocations. EVOC 2000. Version 5 Avril 2002. M anuel. [site da Internet] Disponível em: http:/ /www.pucsp.br/pos/ped/rsee/evoc.htm

20. Vergès $P$. L'evocation de l'agent: une méthode pour la definition du noyau central d'une representation. Bulletin de Psychologie 1992; 45(405):203-209.

Artigo apresentado em 27/09/2007

Aprovado em 04/03/2008

Versão final apresentada em 31/03/2008 